\title{
Reinforcement of steel beam-to-double column moment connection using side plates
}

\author{
Yousef Zandi*, Afram Keivani \\ Department of Engineering, Faculty of Civil Engineering, Tabriz Branch, Islamic Azad University, Tabriz, Iran. \\ *Correspondence: zandi@iaut.ac.ir
}

SUBMITTED: 25 October 2021; REVISED: 11 November 2021; ACCEPTED: 12 November 2021

\begin{abstract}
One of the disadvantages of conventional steel structures in Iran is the common I-shaped beam to the double-column fixed connection that does not perform well against seismic loads. This article uses the side plate to modify and optimize the connection. Using this new geometry, the beam-to-column direct connection is eliminated, and there is no longer any concern about the brittle fracture of the penetration weld of the beam-to-column connection and the weakness of the panel zone that occurs in the common fixed connections. In addition, by eliminating the direct transfer of beam flange force to the double-column connection plate, the problem of deformation, complexity, or buckling of the cover plate of the column is spontaneously removed. In this paper, in order to investigate the nonlinear behavior of beamto-double column connection systems, a number of three-dimensional finite element models under the effect of cyclic loading have been analyzed. The results show that the beam-to-double column connection using the side plates has good strength and ductility and can be used in special moment frames for seismic areas.
\end{abstract}

KEYWORDS: : Steel structure; fixed connection; side plate; composite column; double column; earthquake resistance structure

\section{Introduction}

Moment frames I-shaped beams and double columns are widely used in Iran. Double columns are usually made of a combination of two I-shaped profiles (channel beams) connected by a plate or clamp (laced column). In double columns, the connection plates of two profiles are connected at only two length edges using corner welding. This plate is very ductile and does not have a good connection to the flange of the column, and, due to the force applied, the flange of the beam will have deformation, complexity, and buckling. This deformation will also dramatically decrease the axial loading capacity of the column [1-4].

Although many studies have been conducted in recent years on the behavior of moment connections during earthquakes, much of the research has focused on beam-to-wide flange and can-section column connections. To the best of the authors' knowledge, no regular studies on the seismic behavior and performance of moment connections of I-shaped beams to double columns under cyclic loads have been conducted [5-7].

In a study conducted on several examples of static and single-direction beam-to-column connections, it was shown that conventional welding connections were not fully fixed due to 
the weakness of the connection plate and should be considered semi-fixed unless the connection plate operates seamlessly with the two profiles and its intermediate role in power transmission is eliminated in a way [8-11].

On the other hand, many studies conducted after the Northridge and Kobe earthquakes show that the most common type of rapture caused by earthquake at moment connections has been the early brittle fracture at the direct connection area of the beam flange (or force transmission plate) to the column flange (or to the connection plate in double combined columns) by penetration weld. The intense concentration of three-axial stress in the connection area practically moves the plastic joint from the beam into the column and greatly reduces the connection formation capacity.

None of the methods proposed so far to modify conventional moment fixed connections are applicable to the I-shaped beam-to-double column connection. In the system proposed for I beam-to-double column connection in this study, the penetration weld connection of the beam end to the column is completely eliminated and instead, full-depth side plates for transferring moment and shear force from the beam end to the column are used. The side plates are plates that are parallel to the beam on both sides of the beam and are welded to the beam flanges and, on one side, to the column (Figure 1). In the proposed system, the upper end of the beam is not in contact with the column at all, contrary to conventional methods, and it is separated fully. In other words, the moment transmission mechanism at the proposed connection is quite different from the conventional methods in beam-to-column moment connections.

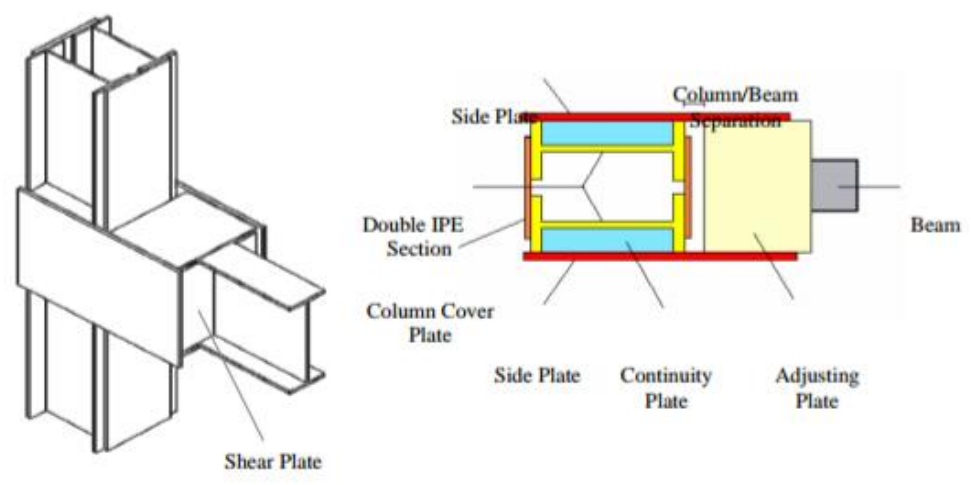

Figure 1. Beam-to-double column connection using the side plates.

In this system, the moment transmission from beam to column is done through the side plates rather than using the direct beam-to-column connection path. The moment of beam end acts as a pair of forces on the upper and lower flange of the beam. This pair of forces is transmitted through corner welds to the upper and lower cover plates (plates arranged between the beam and column flange) and then, through the two plates, is transmitted to the side plates and finally, through the corner welds, transmits to the column.

Although transmission of shear force may be done similar to conventional methods by beam to column and transmitted to the proposed system through two rectangular shear plates embedded on either side of the beam. The geometric details of the beam-to-double column connection using the side plate are shown in Fig. 2.

Separating the end of the beam from the column removes all concerns related to the Ishaped beam-to-double column connection (and not just modifications). By eliminating the 
direct connection of the beam flange to the cover plate on the double column, all problems caused by the penetration weld of beam flange to column flange, brittle fracture, triaxial stress effect, and stress concentration, as well as the high deformation or buckling of the cover plate, are completely eliminated.

The philosophy used in this inventive method of moment transmission was first applied to can columns in 1974 by Blais [11] and then in 1975 by Giroux and Picard [12]. The use of side plates in 1996 was also examined by Atuso et al. [13] and Sabol et al. [14]. In each of the above methods, there were problems. In all the aforementioned connections, the connection of each beam flange is done by a separate side plate.

In 1998, Houghton [15] for the first time, instead of using a separate and narrow side plate for each beam flange, he connected both flanges of each side of the beam to the column flange by a full depth plate. Using this method removed previous problems using side plates. He successfully used this method to connect I-shaped beams to cans and wide-flanged columns. Under the influence of unidirectional and cyclic loads, the use of side plates to connect I-shaped beams to wide flange columns was investigated by Dilmi and Ashraf [16]. For the first time, the application of this method was investigated by Dilmi and Shiravand [17] for double columns, and good results were obtained.

\section{Modeling to investigate the connection behavior}

In this research, the finite element method was used to study the behavior of the beam-tocolumn connection, and ANSYS software was used. IPE sections are intended for double beams and columns. The double column components are connected to each other by a fulllength connection plate. The dimensions of all the models and specifications of the profiles and plates used are shown in Tables 1, Table 2, and Figure 2.

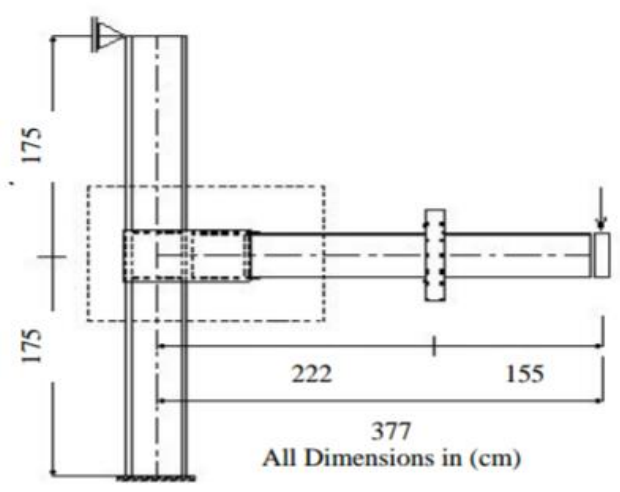

Figure 2. General geometry of the beam-to-adouble column connection model using side plates.

The thickness and dimensions of the side plates are selected according to the results of previous studies by Dilma and Ashraf [9]. In Table 2, the parameters h spa, 1 spa, and t spa are equal to the height and length of the side plates, $t$ cove, 1 cove, and $b$ cove, respectively, are equal to the thickness, length, and width of the cover plates (plates of arranging distance between the beam and column flange), and $t$ con and $t$ shy are the thickness of the continuity plates and shear plates, respectively. The materials of the models under study are considered steel sd-37. A bilinear model is used to model its behavior since this type of steel has elastoplastic behavior with strain hardening. The coefficient of elasticity of steel is $210 \mathrm{GPa}$. The yield stress of steel 
is considered to be $240 \mathrm{MPa}$ and the second-line slope of the model of material behavior is also considered to be $0.65 \mathrm{GPa}$. It is a kinetic hardening law, and the von Mises yield criterion is considered for steel. The boundary conditions are the same for all models. The degrees of freedom of the nodes at the column's foot are completely bound in three directions, while the nodes at the column's top are bound in two directions perpendicular to the column axis but free in the column axis. The SOLID45 element in the ANSYS software is used for modeling.

Table 1. Double Dimensions and Columns of Models Considered.

\begin{tabular}{cccccccc}
\hline Model & $\begin{array}{c}\text { Profile } \\
\text { of beam }\end{array}$ & $\begin{array}{c}\text { Profile of } \\
\text { column }\end{array}$ & $\begin{array}{c}\text { Corner to } \\
\text { the corner } \\
\text { of columns }\end{array}$ & $\begin{array}{c}\text { Dimensions of } \\
\text { column cover } \\
\text { plate }\end{array}$ & $\begin{array}{c}\text { Width of } \\
\text { beam } \\
\text { flange }\end{array}$ & $\begin{array}{c}\text { Thickness } \\
\text { of beam } \\
\text { flange }\end{array}$ & $\begin{array}{c}\text { Thickness } \\
\text { of beam }\end{array}$ \\
\hline SP-A-01 & IPE300 & 2 IPE240 & 180 & $250 \times 10$ & 150 & 10.7 \\
SP-A-02 & IPE300 & 2IPE300 & 200 & $300 \times 15$ & 150 & 10.7 \\
SP-A-03 & IPE400 & 2IPE240 & 180 & $250 \times 10$ & 180 & 13.5 \\
SP-A-04 & IPE400 & 2IPE300 & 200 & $300 \times 15$ & 180 & 13.5 \\
\hline
\end{tabular}

All dimensions are in millimeters

Table 2. Detail dimensions of beam-to-double column connections using side plates.

\begin{tabular}{ccccccccc}
\hline MODEL & $\mathbf{T}_{\text {sp }}$ & $\mathbf{L}_{\mathbf{s p}}$ & $\mathbf{H}_{\mathbf{s p}}$ & $\mathbf{T}_{\mathbf{c o v}}$ & $\mathbf{L}_{\mathbf{c o v}}$ & $\mathbf{B}_{\text {cov }}$ & $\mathbf{T}_{\mathbf{c o n}}$ & $\mathbf{T}_{\text {sh }}$ \\
\hline SP-A-01 & 15 & 550 & 350 & 10 & 300 & 300 & 10 & 10 \\
SP-A-02 & 15 & 600 & 350 & 10 & 300 & 350 & 10 & 10 \\
SP-A-03 & 20 & 600 & 450 & 12 & 350 & 300 & 12 & 12 \\
SP-A-04 & 20 & 650 & 450 & 12 & 350 & 350 & 12 & 12 \\
\hline
\end{tabular}

All dimensions are in millimeters

Applying load is done as displacement on the beam tip and in the upright direction. The displacements have been applied in both unidirectional and cyclic ways to investigate the connection behavior both under gravity loads and under cyclic loads such as earthquakes. The unidirectional applied displacement of the equation of rotational angle is considered equal to 0.06 radians for the beam (Fig. 3a). The cyclical applied displacement has also been carried out in accordance with SAC97 [19]. This method of cyclic loading has also been proposed by FEMA350 [11] and the AISC seismic regulation of steel structures. The cyclic loading curve will be in accordance with Fig. 3b, depending on the location change applied to the models. The cyclically applied displacement to a rotational angle is considered equal to 0.06 radians, which is in accordance with FEMA350 [20]. The minimum required limit is to maintain and sustain a connection in special moment frames (SMFs).
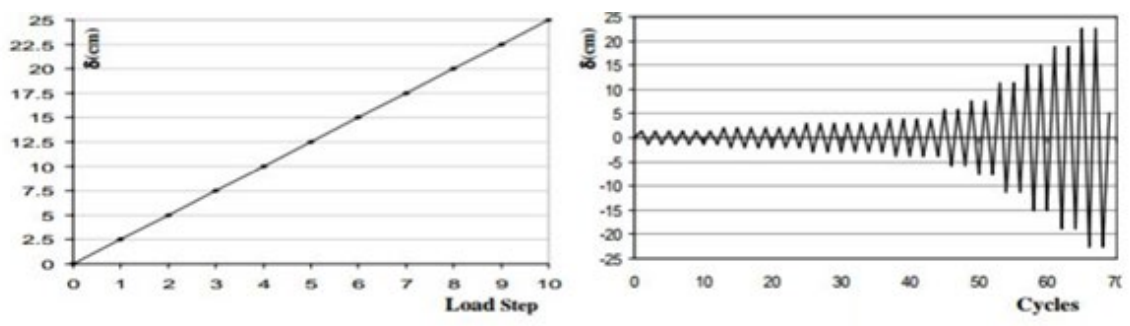

Figure 3. Loading applied to the models: unidirectional loading (left) and cyclic loading (right)

According to the loading pattern on the models under study, due to the entry of the beam into the plastic zone under cyclic loading, as well as the acceleration of the local buckling of the flange and beam due to the entry into the nonlinear area and the effects of continuous loading and unloading, nonlinear analysis seems necessary. Therefore, to study the proposed 
connection behavior and to match the results with reality, all analyses are performed nonlinearly, considering the effects of the "material" and "geometric" nonlinear behaviors.

\section{Reviewing the results}

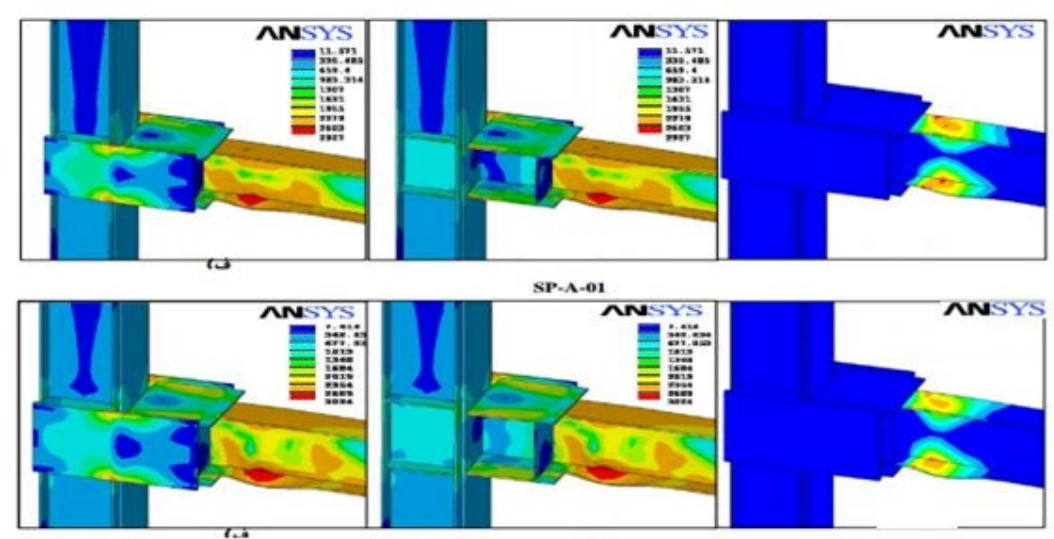

Figure 4. Distribution of stress and strain on beam-to-double column connection using side plates affected by unidirectional load for SP-A04, SP-A-01 models.

The von Mises stress distribution is represented by the unidirectional and cyclic loads, typically for the SP-A-04 and SP-A-01 models in Figures 4, respectively. The front side plate is hypothetically removed in figures B-4 and B-5 to demonstrate how stress is distributed at the panel zone. According to the stress contours, it is observed that the plastic connection site has moved from the connection zone to the beam, which means that there is no further concern about the sudden brittle fracture. Figures $4 \mathrm{~b}$ and $5 \mathrm{~b}$ show that the stresses at the panel zone remain at low limits of elastic due to unidirectional and cyclic loads, and with two full-depth side plates, there is no problem in the panel zone.

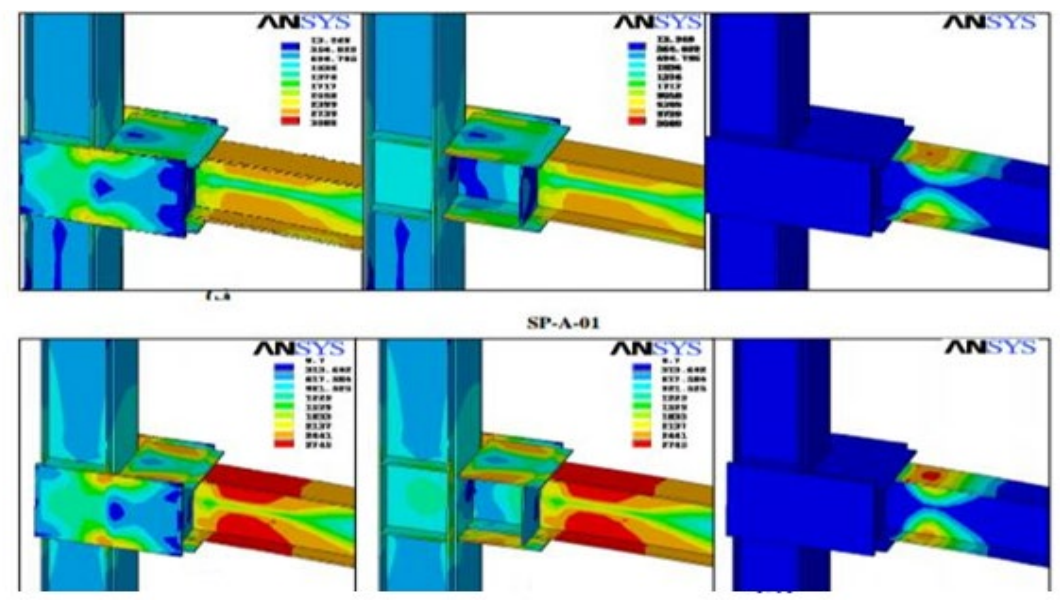

Figure 5. Distribution of stress and strain in beam-to-double column connection using side plates affected by cyclic load for SP-A-04, SP-A-01 models.

Under unidirectional and cyclic loads, the equivalent plastic strain distribution for sample models is shown in Figure 4 and Figure 5. These figures indicate that all plastic deformation occurred during the transformation and the connection has the potential for good ductility. The stress distribution obtained in Figures 1 and 2 shows that the stress on the connection plate of the two column profiles is also placed at very low limits. The separation 
between the end of the beam and the column makes it impossible to directly enter the load on the cover plate. Therefore, there is no problem here with the weakness of the plate against the deformation, tensile and buckling caused by the direct connection of the beam flange.

The moment-to-rotation diagram of the connections of SP-A-01 to SP-A-04 models affected by the unidirectional loads is presented in Figure 6. Also, the cover of the curves from the moment-rotation hysteresis curves for the investigated models is shown in Fig. 2. In these figures, the moment capacity of the plastic beam (M P) is shown with a line. The moment strengths obtained for the models under study are both affected by unidirectional and cyclic loads higher than the moment capacity of the plastic beam, and until the final resistance is reached, the resulting curves are upward, so the connection has very good resistance and creates a plastic joint in the beam. Also, due to the formation of a plastic joint in the beam, the size of the column cross-section does not have a significant effect on the plastic behavior of the connection and only increases the stiffness of the connection in the elastic region. As it can be seen by comparing Figures 6 and 7, the moment-rotation curve obtained under unidirectional loads did not decrease as compared to cyclic loads due to the lack of local buckling under unidirectional loads. This is also evident in Fig. 4, where no buckling is observed in the beams and connections studied.
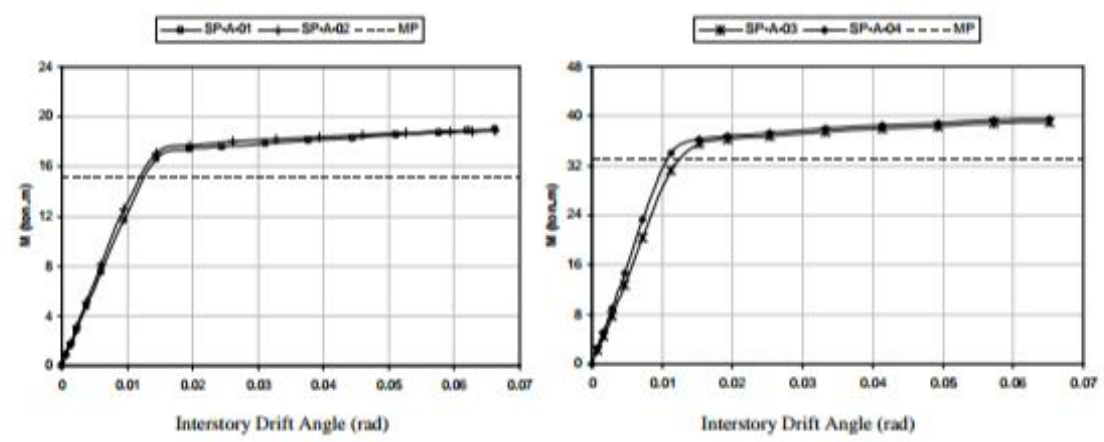

Figure 6. Moment-rotation curves for model SP-A-01 to SP-A-04 affected by unidirectional loads.

But due to cyclic loads, as can be seen in Fig. 7, the moment-rotation curves fall at angles higher than 0.05 radians due to the local buckling in the flange and beam. The local buckling created in the last cycles of cyclic loading can be seen for the model models in Fig. 5 .
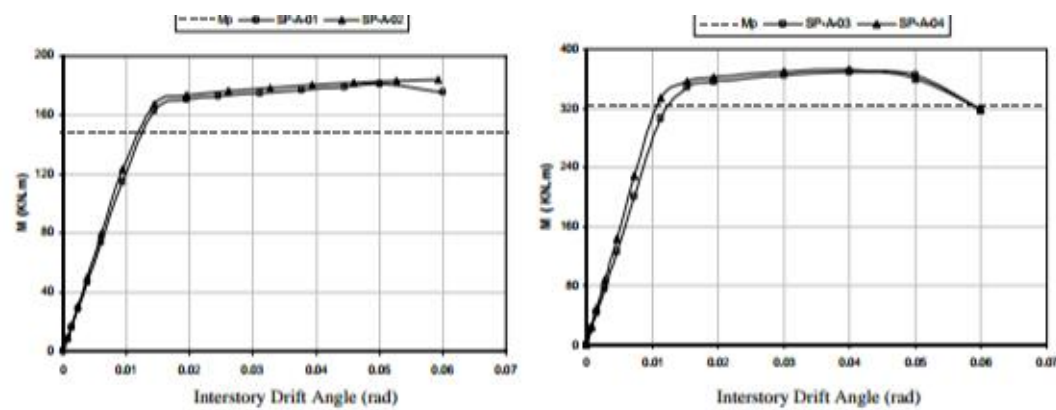

Figure 7. moment-rotation curves for model SP-A-01 to SP-A-04 affected by cyclic loads

The larger the beam cross section, the earlier the start of the fall in the connection resistance will occur and the smaller the rotation angles. As the height of the beam increases, the possibility of local buckling in the beam also increases. Buckling reduces connection 
resistance; however, it should be noted that this buckling occurs at angles greater than 0.04 radians, and thus there is no weakness or resistance fall in the connection before reaching this rotation angle based on FEMA350 and AISC [11], which is known as the minimum rotation angle for a special moment rigid frame (SMF).

\section{Conclusions}

A beam-double column connection system using side plates is capable of transferring all the moment capacity of the plastic beam to the column and forming a plastic joint inside the beam. Therefore, this connection system falls into the category of fully resistant connections. Due to the formation of a plastic joint inside the beam, the beam to double column connection using the side plates shows good rotational capacity, so that without drastically reducing the resistance, it can reach rotational angles of 0.04 radians or more. Therefore, this connection is a fully formed connection and can be used in special moment strength frames (SMFs). Due to the transmission path of power, the tensile force of the beam flange of the double column cover plate is not practically applied and is transmitted to the column through the side plates, thereby the large deformation of the double column covers due to its direct tensile is removed on its own.

\section{Conflicts of Interest}

The authors declare no conflict of interest.

\section{References}

[1] Shariati, M.; Rafie, S.; Mehrabi, P.; Zandi, Y.; Fooladvand, R.; Gharehaghaj, B.; Shariat, A.; Trung, N.T.; Salih, M.N.A., Poi-Ngian, S. (2019). Experimental investigation on the effect of cementitious materials on fresh and mechanical properties of self-consolidating concrete. Advances in Concrete Construction, 8, 225-237. http://dx.doi.org/10.12989/acc.2019.8.3.225.

[2] Zanadi Y.; Akpinar, M.V. (2012). An experimental study on separately ground and together grinding Portland slag cement strength properties. Research Journal of Recent Science, 1, $27-$ 40 .

[3] Zandi, Y.; Akpinar, M.V. (2012). Evaluation of internal resistance in asphalt concretes. International Journal of Concrete Structures and Materials, 6, 247-250. http://dx.doi.org/10.1007/s40069-012-0021-0.

[4] Shariati, M.; Heiati, A.; Zandi, Y.; Laka, H.; Toghroli, A.; Kianmehr, P.; Safa, M.; Salih, M.N. A.; Poi-Ngian, S. (2019). Application of waste tire rubber aggregate in porous concrete. Smart Structures and Systems, 24, 553-566. https://doi.org/10.12989/sss.2019.24.4.553.

[5] Nosrati, A.; Zandi, Y.; Shariati, M.; Khademi, K.; Aliabad, M.D.; Marto, A.; Mu'azu, M.A.; Ghanbari, E.; Mahdizadeh, M.B.; Shariati A.; Khorami, M. (2018). Portland cement structure and its major oxides and fineness. Smart Structures and System, 22, 425-432. https://doi.org/10.12989/sss.2018.22.4.425.

[6] Zandi, Y.; Burnaz, O.; Durmus, A. (2012). Determining the temperature distributions of fire exposed reinforced concrete cross sections with different methods. Research Journal of Environmental and Earth Sciences, 4, 782-788.

[7] Yasemin, A.; Zandi, Yousef. (2009). Advantages of using marl in concrete," 2nd International Conference on Concrete Technology, Tabriz, Iran, 18-25. 
[8] Zandi, Y.; Alayi, M (2019). Effect of comparison of Ardabil pozzuoli cement and type 2 Sufyan cement compressive strength viewpoints and improvement solutions. Journal of Structural and Construction Engineering, 6, 95-110. https://dx.doi.org/10.22065/jsce.2018.117984.1454.

[9] Zandi, Y. (2013) Effect of mix design on restrained shrinkage of concrete. Bulletin of Environment and Life Sciences, 2, 13-20.

[10] Blais, R. (1974). Joints Soudes Pour Profiles Tubulaires, MSc Thesis, Civil Engineering Department, Laval University, Canada.

[11] Picard, A.; Giroux, Y.M. (1976). Moment Connection between Wide Flange Beams and Square Tubular Columns. Canadian Journal of Civil Engineering, 3, 174-185. https://doi.org/10.1139/176-018.

[12] Atsuo, T.; Hiroshi, M.; Akiyoshi, I. (1996). Statical Characteristics of WF Beam to RHS Column Connections Using Vertical Stiffeners. $11^{\text {th }}$ World Conference on Earthquake Engineering, Acapulco, Mexico.

[13] Sabol, T.A.; Engelhardt, M.D.; Aboutaha R.S.; Frank K.H. (1996). Overview of the AISC Northridge Moment Connection Test Program. 11 ${ }^{\text {th }}$ World Conference on Earthquake Engineering. Acapulco, Mexico.

[14] Houghton, D.L. (1998). The Sideplate Moment Connection: A Design Breakthrough Eliminating Recognized Vulnerabilities in Steel Moment Frame Connections. Proceedings of the $2^{\text {nd }}$ World Conference on Steel Construction. San Sebastian, Spain.

[15] Deylami, A.; Ashraf, R. (2003). Moment Resisting Connection with Sideplate. $9^{\text {th }}$ East AsiaPacific Conference on Structural Engineering and Construction. Bali, Indonesia.

[16] Deylami, A.; Shiravand, M.R. (2005). Moment Connection of Steel Built-up Column Using Side Plates", $4^{\text {th }}$ International Conference on Steel Structure. Shanghai, China.

[17] Deylami, A.; Ashraf, H. (2004). Moment Resisting Connection with Sideplate (Geometric Aspect)", $13^{\text {th }}$ World Conference on Earthquake Engineering (13WCEE). Vancouver, Canada.

[18] Clark P. (1997). Protocol for Fabrication, Inspection, Testing, and Documentation of BeamColumn Connection Test and other Experimental Specimen, SAC Joint Venture. Sacramento, USA.

[19] Federal Emergency Management Agency (FEMA), Recommended Seismic Design Criteria for New Welded Steel Moment Frame Buildings, (FEMA-350), SAC Joint Venture, Sacramento, California, 2000.

[20] American Institute of Steel Construction (2002) Seismic Provisions for Structural Steel Buildings. Chicago, USA.

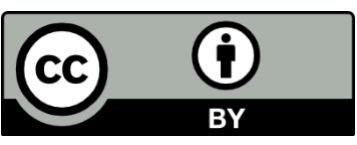

(C) 2021 by the authors. This article is an open access article distributed under the terms and conditions of the Creative Commons Attribution (CC BY) license (http://creativecommons.org/licenses/by/4.0/). 